\title{
Prática de correção textual e formação de escreventes: viés dialógico
}

\author{
Norma Seltzer Goldstein* \\ Viviane Dinês de Oliveira Ribeiro Bartho**
}

\begin{abstract}
Resumo
Sendo o dialogismo processo inerente à linguagem, seria paradoxal considerar uma produção de texto - réplica dialógica escrita - como monológica ou, mesmo, como incorreta. Na escola, porém, algumas correções de texto são realizadas segundo esse paradoxo. A avaliação escolar desconsidera o princípio da dialogia, ao aplicar critérios de correção que distinguem a boa réplica da má, caso este em que o texto é considerado inadequado. Discutimos alguns desses critérios, de modo a observar sua aplicabilidade na perspectiva do dialogismo. Elegemos analisar um texto pelo viés de seu dialogismo constitutivo e propor essa perspectiva para a avaliação de texto, de modo a operar na formação do aluno-escrevente e do professor. A concepção de "erro" é relativa: pode traduzir a não aprendizagem de algum tópico pelo aluno; e pode, ainda, ser indício da necessidade de reflexão sobre a prática pedagógica, sendo, neste caso, uma oportunidade de formação docente. Propomos, a partir de exemplificação, um olhar dialógico e inclusivo para os textos dos alunos, trabalhando aspectos constitutivos de suas próprias produções. A nosso ver, tanto a produção quanto a avaliação da produção são atos responsivos dialógicos que afetam, na relação de alteridade, a constituição dos sujeitos que lidam com a escrita e podem, assim, ensinar e aprender mutuamente.
\end{abstract}

Palavras-chave: Dialogismo. Produção de réplicas escritas. Avaliação de textos na escola. Formação discente e docente na e pela escrita.

\section{Pratique de correction textuelle et formation d'étudiants en tant que producteurs de textes: biais dialogique \\ Résumé}

Le dialogisme étant un processus inhérent au langage, il est paradoxal de considérer une production de texte - une réplique dialogique écrite — comme monologique ou comme incorrecte. Cependant, à l'école, des corrections de texte sont parfois effectuées suivant ce paradoxe. L'évaluation scolaire ne tient pas compte du principe du dialogue, lorsqu'elle applique des critères de correction qui délimitent ce qui serait une bonne ou une mauvaise réponse; et dans ce cas-là le texte est annulé. Nous discutons ces critères afin d'observer leur applicabilité selon une perspective du dialogisme. Nous avons choisi d'analyser un texte à la lumière de son dialogisme constitutif et de proposer la même perspective pour l'évaluation d'une production écrite, comme si elle pouvait jouer un rôle dans la formation de l'élève et de l'enseignant. Le concept de "faute" est relatif: il peut indiquer que certains aspects n'auront pas été apris par l'étudiant; et peut encore indiquer le besoin d'une réflexion sur la pratique pédagogique, c'est à dire, contribuer à la formation des enseignants. Nous proposons, à partir d'exemples, un regard dialogique et inclusif sur les textes des étudiants, en considérant les aspects constitutifs de leurs productions énonciatives. Cette perspective, à notre avis, peut contribuer à la formation des étudiants et aussi à celle des enseignants. La production et son évaluation sont des actions dialogiques qui affectent le rapport d'altérité, la constitution des sujets, l'occasion d'enseigner et d'aprendre par l'intération.

Mots-clés: Dialogisme. Production de répliques écrites. Evaluation de la production des étudiants. Formation des étudiants et des enseignants par le biais dialogique de l'écriture.

Recebido: $11 / 03 / 2019$

Aceito: 16/07/2019

\footnotetext{
* Universidade de São Paulo (USP). Mestre e Doutora em Teoria da Literatura e Literatura Comparada. Atualmente é professora sênior do Programa de Pós-Graduação em Filologia e Língua Portuguesa da Universidade de São Paulo. Desenvolve e orienta pesquisas na área de Linguística Aplicada

** Universidade de São Paulo (USP) e Instituto Federal de São Paulo (IFPS). Mestra em Linguística Aplicada e Doutoranda em Letras. Atualmente é professora de Ensino Básico Técnico e Tecnológico do IFSP, campus de Campos do Jordão.
} 
[...] toda palavra comporta duas faces. Ela é determinada tanto pelo fato de que procede de alguém, como pelo fato de que se dirige para alguém. Ela constitui justamente o produto da interação do locutor e do ouvinte. Toda palavra serve de expressão a um em relação ao outro. Através da palavra, defino-me em relação ao outro, isto é, em última análise, em relação à coletividade. A palavra é uma espécie de ponte lançada entre mim e os outros. Se ela se apoia sobre mim numa extremidade, na outra apoia-se sobre o meu interlocutor. A palavra é o território comum do locutor e do interlocutor. (BAKHTIN, 2006, p. 117).

\section{Introdução}

Os enunciados concretos são constitutivamente dialógicos (BAKHTIN, 2006), resultantes de um processo de diálogo intrínseco e presumido, segundo o qual um ato de linguagem responde a outros e antecipa futuras respostas, em uma interação recíproca e imbricada. Todos os enunciados realizados são, portanto, réplicas discursivas. No entanto, pensando especificamente em réplicas escritas, tal constituição pode ficar mascarada na organização e materialidade verbal do texto ou pode ser apresentada explicitamente, por meio de recursos enunciativos que permitam entrever a dialogia estabelecida pelo leitor-escrevente. Esses recursos provocam, quando explícitos, efeitos polifônicos e, quando subentendidos, podem instaurar no texto efeitos monofônicos (BARROS, 2011). No segundo caso, os enunciados passam a ter aspecto monologizado, como se pudessem ter sido engendrados sob o simulacro da monologia.

No contexto escolar, muitas vezes, a leitura e a escrita são realizadas sob esse simulacro, devido a um conjunto de fatores que passam pela própria organização institucional, pelas concepções de leitura e mesmo pela visão de linguagem dos sujeitos, pelas práticas pedagógicas que envolvem o trabalho com os enunciados em sala de aula e por toda a situação de produção, situada e sócio-histórica, que operam no modo como os alunos replicam e são influenciados a replicar.

Este artigo $^{1}$ enfatizará algumas práticas pedagógicas relacionadas ao olhar do professor sobre a réplica escrita de seus alunos; olhar este que é parte do processo de formação tanto do alunoescrevente, como do professor-avaliador-escrevente, entendendo o processo de ensino-aprendizagem como processo em direção dupla, isto é, que age no aluno e também no professor. Nesse sentido, a correção de texto na escola pode ser considerada como formadora dos atores envolvidos: quando o professor orienta o processo de escrita de seu aluno por meio da avaliação de textos, ele também olha para si próprio, como também escrevente e enunciador de réplicas. A própria correção é uma réplica, que produzirá efeitos discursivos materializados em respostas dadas, futuramente, pelos alunos.

É objetivo, em aulas de língua materna, voltadas à formação dos alunos, a adoção de estratégias e metodologias que lhes permitam realizar réplicas autônomas, críticas, abertas ao diálogo com outras que serão projetadas. Nesse processo, inclui-se a reflexão sobre o modo constitutivo dos enunciados e sobre os recursos enunciativos que podem ser empregados ou não, em função do tipo de réplica que se busca elaborar. Para tanto, a heterogeneidade dos sujeitos, que marca a linguagem deles, não pode ser concebida como traço negativo.

Buscamos, neste artigo, discutir alguns critérios avaliativos de réplicas escritas produzidas por alunos em contexto escolar. Assim, delimitamos dois objetivos específicos: analisar um texto produzido ${ }^{2}$ por um aluno do Ensino Médio, considerando seus aspectos dialógicos constitutivos; e propor, no decorrer das reflexões teóricas e analíticas, uma perspectiva de avaliação de textos que contribua com a formação de alunos e professores, escreventes ativos e dialógicos. Nesse contexto, algumas

$1 \mathrm{O}$ presente artigo faz parte da tese de doutorado em Letras, pela Universidade de São Paulo, a ser defendida em dezembro de 2019 pela autora Viviane Bartho, orientada por N. Goldstein.

2 A produção textual a ser analisada foi delimitada do corpus de pesquisa de doutorado referida na nota 1. 
concepções imbricadas na avaliação de produções escritas serão discutidas, por exemplo, a própria noção de "erro". Não pretendemos descrever uma sistematização fechada e homogeneizada, que se apresente pronta a aplicações em sala de aula. Apenas buscamos contribuir com as práticas docentes em relação aos textos discentes, de modo a apontar algumas questões operacionais. Acreditamos que essas práticas, embora direcionadas aos alunos, influenciam, como já foi dito, a própria formação do professor, como sujeito que também replica dialogicamente.

Iniciamos pela reflexão sobre a escrita como ato dialógico. Em seguida, apresentamos a análise de um texto segundo sua constituição dialógica. A partir dessa análise, discutimos alguns critérios específicos da avaliação de texto na escola, a fim de desvendar aspectos que ficam excluídos, mas que podem ser observados em uma abordagem essencialmente dialógica. Finalmente, tecemos comentários acerca da avaliação de produção de textos dos alunos, a partir de práticas de ensino recorrentes na escola e refletimos sobre a concepção de "erro".

\section{Escrita como ato dialógico}

Abordamos aqui a base teórica principal para as reflexões a seguir. A epígrafe com a qual iniciamos o trabalho expressa o princípio dialógico da linguagem, que permeia toda a obra bakhtiniana. Por esse princípio, todo ato de linguagem seria uma forma de resposta a enunciados já realizados, a qual, por sua vez, incita novas atitudes responsivas (BAKHTIN, 2006). Assim, o enunciado concreto é, necessariamente, constituído de discursos outros e projeta outros tantos como respostas futuras, incluindo as formas de silêncio. Essa dinâmica inerente às relações sociais rege os atos enunciativos e revela a consequente heterogeneidade dos discursos e dos sujeitos, efeito das relações de alteridade.

As considerações em torno do dialogismo orientam a compreensão do próprio funcionamento do sentido. Como o processo de interação enunciativa é contínuo, em que um enunciado está ancorado a outro, em inter-relação tensa, nem sempre de consonância, mas também de dissonância, o sentido sempre é dado (ampliado ou modificado) pelo outro (BAKHTIN, 2006). A construção dos sentidos é, pois, inacabada, sempre dependente da ação do outro com quem (ou com o quê) se dialoga. Tem-se, assim, o eu constituído sempre do outro, bem como os discursos ditos carregam os já-ditos.

A linguagem, segundo explica Brandão (2017), é atividade constitutiva do sujeito, atividade enunciativa e atividade de interação social. Interessa-nos, para este trabalho, a linguagem enquanto atividade de interação, não apenas dual e imediata, entre um "eu" e um "tu"; mas, como apontava Bakhtin (2006), uma interação ampla, com um "outro" social, histórico, discursivo. Nas palavras de Brandão (2017, p. 152), em interpretação ao pensamento bakhtiniano: “A natureza social da enunciação é o motor que dá dinamicidade e impulsiona a variabilidade das formas de enunciação e a evolução real da língua". Assim, como meio de economia comunicativa, as interações enunciativas são realizadas por meio de gêneros discursivos, que são realizações enunciativas concretizadas sob características formais, estilísticas e de conteúdo, mais ou menos padronizadas. Esse padrão sofre interferências de forças sociais, culturais e individuais, que podem provocar instabilidade do/no gênero. $\mathrm{O}$ sujeito enunciador lida, portanto, com formas estáveis, que lhe chegam já formatadas e que passam a constituílo, e com brechas no sistema discursivo que lhe permitem emergir em sua singularidade (BRANDÃO, 2017). Não há enunciado tão padronizado que só traduza o trabalho reprodutivo e não o produtivocriativo. Há gêneros mais propícios a um trabalho individual em sua estrutura, e outros, mais fechados a essa proposta. Essa maneira de observação dos produtos da enunciação está relacionada ao conceito de estrutura e acontecimento em Pêcheux (2015), quando o autor discorre sobre o sentido sedimentado, naturalizado, que chega aos sujeitos como evidência, funcionando como estrutura pré-construída, mas que, na verdade, seriam repetições imperfeitas, pois se realizam conjugadas a sujeitos diferentes, em contextos enunciativos diferentes, constituindo o acontecimento discursivo inédito. 
Neste artigo, enfocamos réplicas escritas, produzidas em contexto escolar, como gêneros do discurso que são materializados em um processo de dialogismo, mas cujo caráter essencialmente dialógico segundo o qual seria possível observar o trabalho do escrevente, do "eu" enunciador, na estrutura fica subjugado, muitas vezes, a um olhar apenas para a estereotipia genérica. Consideramos que uma abordagem da produção de textos dos alunos levando em conta seus aspectos plurais, de estabilidade e instabilidade, poderia contribuir para a formação de escreventes mais autônomos para replicar. É a partir dessa proposta que segue a análise do texto delimitado.

\section{Análise de produção textual pelo viés do dialogismo}

Apresentamos, neste item, a análise de um texto considerado como réplica de leitura de um aluno do Ensino Médio de uma instituição de ensino público federal. Tal réplica é resultante de uma proposta de produção escrita a partir da leitura de duas letras de canções, "Construção", de Chico Buarque, e "Cidadão", do compositor Lúcio Barbosa, interpretada por Zé Ramalho. As músicas foram ouvidas pelos alunos e as letras lhes foram entregues com três intuitos: a) continuação de estudos de aspectos expressivos da linguagem, como as figuras (houve uma sequência de aulas sobre o assunto); b) possibilidade de intertextualidade e interdiscursividade em relação ao livro Vidas secas, de Graciliano Ramos, lido em um bimestre anterior à atividade; e c) realização de uma leitura crítica e dialógica. Embora estivessem claros para o professor, esses objetivos não foram explicitamente verbalizados aos alunos, pois também era pretensão observar se eles se concretizariam naturalmente e de que forma. Como recomendações para a produção, apenas fora estabelecido que escrevessem um texto dissertativo-reflexivo sobre as letras de canções lidas. Não houve determinação de regras. Os enunciados resultantes foram considerados enunciados concretos e, quanto ao gênero discursivo (BAKHTIN, 2003), foram entendidos como “comentários de leitura”. Segue um texto transcrito ipsis litteris, integralmente. Os destaques em itálico, negrito e sublinhado foram inseridos por nós, autoras.

As pessoas sobem em prédios altos para ganhar uma micharia no final do mês muitas pessoas morrem na obra e eles não dão nada para a família em troca então eu acho errado eles exploram as pessoas demais e a falta de serviço no Brasil que atrapalha isso porque muitas pessoas jovens que cursou o ensino médio fez uma boa faculdade e podia estar trabalhando em um bom emprego e vai para as [ilegível para a transcrição] onde trabalha o dia inteiro embaixo de sol quente ou chuva por falta de serviço no Brasil como se falou na música o homem estava admirando o prédio que construiu ai chega um cidadão e pergunta você está admirando ou esta querendo roubar intão isso tem mudar no Brasil é muita injustiça um pessoa ganha 2 mil para ficar sentado sem fazer nada e um pedreiro que fez faculdade ganha $900 \mathrm{R} \$$ por mês por falta de serviço que teve aí teve que ir pra obra pra ganhar seu dinheiro e sustentar a família intão vamo mudar isto.

O texto, numa avaliação institucional, seria mal classificado, levando-se em conta aquilo que a escola espera, sob uma visão basicamente pautada pelo emprego de determinados aspectos: predomínio da norma padrão; uso de elementos coesivos ${ }^{3}$ próprios de um texto dissertativo-expositivo etc., a começar com a aparente falha no processo de referenciação anafórica pela falta de um referente textual para o pronome pessoal "eles", na segunda linha: (“As pessoas sobem em prédios altos para ganhar uma micharia no final do mês muitas pessoas morrem na obra e eles não dão nada para a família em troca"). No entanto, o referente de "eles", bem como a compreensão de quem ou do que se trata, nas partes em itálico no texto, podem ser estabelecidos por meio do resgate do contexto sócio-histórico relacionado às condições trabalhistas no Brasil. De modo geral, os leitores desse texto

3 Tomamos os trabalhos de Koch, como As tramas do texto (KOCH, 2014), para tratar de aspectos de coesão e de coerência textuais aqui referidos. 
saberiam identificar quem são "eles que não dão nada para as famílias dos trabalhadores”, quem são "as pessoas que sobem em prédios e morrem na obra", como termos relacionados às condições exploratórias de trabalho, sobretudo, nas construções civis. Interpretariam, inclusive, por que esses fatos ocorrem. O aluno estabeleceu diálogo com o contexto amplo das relações de trabalho, de forma livre e direta, imaginando que a instituição escolar, especificamente na interlocução com o professor, não deixaria de reconhecer dados contextuais a que também tem acesso nem de presumir a alusão às relações de poder entre empregador e empregado, principalmente no âmbito da construção civil das grandes cidades, em que muitos trabalhadores se submetem a condições subumanas de trabalho e, quando sofrem acidentes, por vezes, deixam de ser indenizados. Essa cena trabalhista, que habita, em certa medida, o imaginário discursivo dos cidadãos, — logo, do professor e do aluno - , permite estabelecer referentes para a coesão exofórica construída pelo escrevente. O movimento dialógico ocorre justamente nos pontos de (aparente) falta de contextualização dos textos lidos pelo aluno e nas referenciações exofóricas, deixando entrever elementos sócio-históricos não diretamente explicitados na leitura que realizou. Esse estilo de diálogo construído revela o pressuposto pelo escrevente de que o leitor de sua réplica conheça os textos lidos, base para a produção, configurando-se como uma aposta de interlocução em direção ao professor, o qual o aluno imagina que, por ter solicitado a leitura e a produção escrita, considere o texto proposto como ponto de partida.

A falta de contextualizações aos moldes acadêmicos, de retomada do já-dito nas letras das canções, de elementos coesivos que, textualmente, sustentariam as referenciações, enfim, a falta desses aspectos desvenda um tipo de interlocução com a instituição que se faz pela recusa ao enquadramento formal instituído. Entendemos que o diálogo com a instituição é marcado pela indiferença ou pela não prioridade dada a ela, o que não deixa de ser um tipo de ação responsiva. Cabe observar que houve um movimento dialógico em direção ao professor, que pode ser considerado como representante da voz institucional. Esse diálogo ocorreria pela aposta no compartilhamento de informações, e esse modo de replicar poderia provocar um efeito monofônico, segundo o qual a escola não reconheceria os diálogos estabelecidos pelo aluno. Nosso modo de ver é diverso. Em vez de falhas no processo de dialogismo, consideramos ter havido a adoção de estratégias discursivas pelo escrevente que apontam para diálogos presumidos. As marcações em itálico, portanto, apontam para o diálogo que o aluno estabelece com discursos que têm como pano de fundo a cena trabalhista, voltado ao professor, como interlocutor que partilha da coerência desse diálogo.

Nesse mesmo movimento dialógico, o escrevente faz uma colagem de um enunciado que consta em uma das letras de canção lida, ou seja, uma reprodução muito próxima do que consta na letra "Cidadão", que é: "Mas me vem um cidadão? E me diz desconfiado? Tu tá aí admirado?/Ou tá querendo roubar?”, a partir do que o escrevente produz: “[...] chega um cidadão e pergunta você está admirando ou esta querendo roubar [...]". Nomeamos esse recurso de colagem, não de paráfrase, porque esta traria traços mais claros de reconstrução linguística, o que não ocorre. O escrevente, então, retira um trecho da letra da canção de forma quase literal, sem marcação de aspas ou outro recurso que delimite a cópia. O enunciado colado consiste, na letra, em uma passagem de discurso direto e, pela forma enunciativa praticamente reprodutora da voz ressoada no texto lido, provoca efeito de monofonia, em que a voz do escrevente é praticamente aquela mesma com a qual dialoga. Em outra parte da réplica, o escrevente reproduz esse discurso direto, numa mescla entre discurso direto e indireto; tal mesclagem produz efeito polifônico, em que ressoam a voz do eu lírico, em discurso indireto (como se falou na música..., isto é, o eu lírico comentou), e a voz de uma personagem que questiona outra: um sujeito, investido da figura do cidadão empregador, indaga se o trabalhador está admirando o prédio ou está querendo roubá-lo.

Já o trecho sublinhado: "[...] e a falta de serviço no Brasil que atrapalha isso porque muitas pessoas jovens que cursou o ensino médio fez uma boa faculdade e podia estar trabalhando em um bom emprego e vai para as [parte ilegível] [...]" desvenda um conhecimento de mundo do escrevente 
trazido à sua réplica, como apoio para a análise da situação retratada nas letras das canções. Esse modo de expressar a compreensão dos textos lidos revela que o aluno os compreendeu e estabeleceu conexões de acordo com seu universo pessoal de conhecimento, vivência e experiência. É uma indicação da história de leituras do aluno.

Os enunciados em negrito são pontos de indicação do modo de apreciação do aluno-leitorescrevente em relação ao tema evocado nos textos lidos e por ele replicados. Essa maneira de apreciar os discursos com os quais dialoga é marcada por traços visíveis de pessoalidade (eu acho errado...), por afirmações categóricas (isso tem mudar no Brasil), pela forma como avalia a situação (como errada, injusta) e pela forma como a explica (é muita injustiça um pessoa ganha 2 mil para ficar sentado sem fazer nada e um pedreiro que fez faculdade ganha 900 R\$ por mês por falta de serviço que teve aí teve que ir pra obra pra ganhar seu dinheiro e sustentar a família intão vamo mudar isto). A falta de pontuação provoca um efeito de leitura acelerada, contínua, sugerindo um tom de indignação e crítica à situação. Interpretamos que tenha havido uma espécie de indignação emocionada que tomou o sujeito, o qual passou a enunciar sem refletir, sem "respirar", sem fazer pausas. Essa característica do enunciado pode ter, ainda, relação com o que o escrevente imagina que seja um leitor crítico para a escola. Mostrando-se como crítico, estabelece diálogo com a instituição, por meio da busca em dar uma resposta à expectativa institucional, antecipada pelo imaginário discursivo.

Os pontos de visível apreciação, bem como os movimentos de dialogismo estabelecidos, de maneira mais ou menos explícita, revelam como o sujeito-leitor leu os textos, quais posicionamentos ele assume em meio ao processo dialógico. É possível perceber, por exemplo, a aproximação entre a formação discursiva da qual enuncia o escrevente e a formação discursiva da qual emanam discursos em favor do trabalhador tido como explorado e injustiçado. A convergência é ratificada pela frase que conclui o texto: "[...] intão vamo mudar isto".

Os recursos discursivos da réplica escrita permitem entrever, ainda, com quem o escrevente dialoga, apontando os atores sociais que são mais caros à sua constituição subjetiva. $\mathrm{O}$ movimento dialógico priorizado nessa réplica foi em direção ao professor, como interlocutor imediato da réplica, e aos atores sociais que compõem a cena trabalhista no Brasil. No entanto, entendemos que a ênfase maior está na forma como se lê e como se replica, importando menos a quem se replica, porque outros possíveis leitores da réplica do aluno, para além do professor, precisariam acessar o enredo das canções para entender o diálogo estabelecido pelo aluno. Não há uma preocupação com o não encontro com outros leitores possíveis; ou o aluno presume que o encontro vai acontecer, independentemente de os dados linguístico-enunciativos serem explicitados ou não. $\mathrm{O}$ escrevente não antecipa possíveis equívocos ou não compreensões da sua réplica. É uma réplica, portanto, pouco preocupada com o "leitor-avaliador" e mais preocupada em “querer dizer" e manifestar o próprio ponto de vista.

O modo de ler e replicar concretizado na produção escrita pode levar a figura do professor, na função de avaliador, a se prender ao aspecto organizador da coesão e coerência do texto e a outros aspectos recomendados em propostas de produção escrita e, assim, com base nesses critérios, desconsiderar a dialogia inerente à réplica. É quase desnecessário comentar que o texto em análise mereceria um cuidadoso trabalho de reescrita, conforme sugere Franchi (2006), que pudesse ampliar as possibilidades de adoção de estratégias polifônicas que deem ao texto mais força de posicionamento em relação às vozes sociais que o compõem. A força de posicionamento está atrelada à probabilidade de ser ouvido e entendido pelo outro, isto é, está associada às condições de participações discursivas mais efetivas. Se a intenção, contudo, for avaliar a leitura das letras das canções realizada pelo aluno e a forma como replica por meio da escrita, consideramos que o enfoque no aspecto dialógico evidencia como elas ocorreram. 


\section{Reflexão sobre alguns critérios de correção textual}

A análise do item anterior ocasiona a discussão sobre alguns critérios de avaliação usados na correção de textos escolares, especificamente textos organizados pelo modo dissertativo e dissertativoopinativo. Essa discussão passa pelo questionamento da possibilidade ou não da aplicabilidade da teoria bakhtiniana em práticas docentes que visam à formação escrita dos alunos.

Dois critérios que salientamos para esta discussão aparecem como constantes na recomendação a textos dissertativos e dissertativo-opinativos: legibilidade (clareza textual, aspectos de coesão e de coerência) e emprego da objetividade. Esses critérios, quando não explícitos em grades de correção, funcionam como itens internalizados ao longo da formação e atuação do professor em relação à correção de textos, conforme detectamos no decorrer de nossas experiências docentes.

Primeiramente, quanto à legibilidade, sobretudo no que diz respeito aos mecanismos da coesão e da coerência, são recomendadas estratégias discursivas estudadas e aprofundadas, principalmente, no âmbito da Linguística Textual, com a definição de texto como uma unidade completa de sentido. Assim, os mecanismos linguísticos precisariam guiar e auxiliar a compreensão do leitor. A preocupação em elaborar o texto como um tecido autossuficiente a ser compreendido, muitas vezes, é presumida em recomendações para que o escrevente faça uma contextualização inicial (no caso do texto analisado, seria uma paráfrase dos textos lidos e comentados), em seu texto, referente ao que se vai desenvolver ao longo dele, a fim de contribuir para a construção de uma textualidade fechada, que ofereça aos futuros leitores informações esclarecedoras, na própria réplica, sem que eles precisem ler os textos impulsionadores dessa réplica. Esse modo de olhar e avaliar a produção textual pode ser considerado como uma tentativa de negar a heterogeneidade, as contradições e as rupturas discursivas, buscando, ao contrário, uma forma homogênea, completa e coerente, sonhada pelos sujeitos, que são, eles mesmos, heterogêneos, fragmentados e incompletos, mas que enunciam sob a ilusão de origem do sentido e de inteireza identitária (PÊCHEUX, 2014). Quando o aluno não segue as recomendações de legibilidade, denuncia sua condição heterogênea e dialógica; dialógica, por presumir que encontrará um interlocutor em quem seu discurso fará eco. Além disso, a quebra da legibilidade está ligada a uma constituição de sujeito que foge à objetivação escolar. Pode evidenciar, assim, muitas coisas, como a resistência a uma espécie de padronização da forma e do conteúdo, logo, do sujeito. Casos de referência exofórica analisados na réplica acima transcrita podem não ser aceitos por uma visão de texto que vise a conduzir e a controlar a construção de sentido (no caso, um único sentido) pelo leitor. No entanto, a coesão que se apresenta pode ser compreendida como um aspecto do dialogismo e da interação intersubjetiva. O escrevente, apostando no encontro dialógico com seu interlocutor, que compartilha das mesmas informações, considera suficiente a coesão exofórica. Logo, uma falha na legibilidade do texto pode significar "erro", segundo uma determinada visão de correção textual; pode, todavia, revelar uma "correção", no diálogo estabelecido pelo escrevente com vozes presumidas e leitores projetados, permitindo-se entrever em sua singularidade.

Outro critério de avaliação de texto é a recomendação de um tom objetivo (o que não significa neutro) a textos dissertativos ou dissertativo-opinativos, como é o caso da produção transcrita. Nem sempre é possível manter tom objetivo em uma réplica. Em alguns momentos do comentário de leitura analisado (sobretudo nas partes destacadas em negrito), é possível compreender um envolvimento emotivo de indignação que se materializa no enunciado. Esses casos permitem ao professor flagrar a subjetividade dos alunos-escreventes. São momentos, porém, que poderiam ser vistos negativamente, se avaliados pela aplicação rígida do critério da objetividade. No entanto, pela perspectiva bakhtiniana da linguagem, esses pontos de trabalho do "eu" sobre a estrutura do gênero estão relacionados a um modo de dialogismo próprio da linguagem, isto é, são pontos em que o sujeito, em sua atividade de resposta, atua de maneira singular, conjugando o dado/estabelecido com a sua constituição discursiva. Esse olhar pode ampliar as possibilidades de avaliação e de visão dos modos de enunciação presentes nas produções dos alunos. 


\section{Produção escrita na escola: a avaliação e a concepção de "erro"}

As produções escritas desenvolvidas pelos alunos na escola são, na grande maioria das vezes, reproduções de um gênero do discurso trabalhado como modelo. Segundo Geraldi (2006), o processo de interação nos textos passa por uma espécie de falseamento ou prática artificial, pois o interlocutor é quase sempre o mesmo e o sujeito se anula em razão da função que exerce; assim: "[...] Quando o tu-aluno produz linguisticamente, tem sua fala tão marcada pelo eu-professor-escola que sua voz não é voz que fala, mas voz que devolve, reproduz a fala do eu-professor-escola [...]." (GERALDI, 2006, p. 89). Dessa forma, é comum o aluno não se perceber autor da sua própria voz e, na busca por ser bem avaliado, reproduzir uma voz institucionalizada com a qual tem contato nas práticas escolares. Ainda de acordo com Geraldi (2006), há uma diferença entre "redação" e "produção de texto": a primeira seria uma composição linguística fechada em si, padronizada, funcionando como reprodução de sentidos e vozes; a segunda seria a composição de acordo com uma concepção de texto como espaço para a subjetividade. Relacionamos o conceito de "produção de texto", em Geraldi, com o tipo de réplica enunciativa que a escola objetiva desenvolver, a saber, uma réplica crítica que, por seus aspectos polifônicos, vislumbra os movimentos de dialogia, pelos quais se pressupõe o trabalho singular do "eu".

No entanto, esse objetivo escolar nem sempre é alcançado. As réplicas escolares, por vezes, aproximam-se da concepção de "redação". Isso porque, como bem sintetiza Geraldi (1991), além da predominância do ensino gramatical nas aulas de língua materna, o texto é comumente tomado como "modelo" de três formas: objeto de leitura vozeada (oralização da leitura), objeto de imitação (texto lido como modelo para a produção escrita) e objeto de uma fixação de sentidos. Concordamos com o autor e acrescentamos algumas considerações: quanto ao ensino de aspectos gramaticais, atualmente, observamos avanços, principalmente quando são trabalhados em função do texto, de maneira articulada às reflexões sobre os usos dos recursos gramaticais. Apesar disso, ainda é possível observar um ensino tradicional, preconceituoso e descontextualizado, centrado na chamada gramática normativa. Foram obtidos muitos progressos no ensino de língua materna por meio de gêneros do discurso. Segundo Bakhtin (2003), os gêneros são os próprios enunciados concretos que apresentam formas relativamente estáveis, relacionados a aspectos composicionais, à temática e ao estilo de linguagem. O que se percebe, porém, é que o trabalho com a gramática aos moldes tradicionais, com nomenclatura gramatical mecanizada, dá lugar, com frequência, a uma espécie de mecanização, agora, dos gêneros. Assim, o que é tido como "relativamente" estável, abrindo possibilidades para a instabilidade no enunciado ou ao que configura a própria atuação subjetiva, foi compreendido e é, não raras vezes, trabalhado em sala de aula como "totalmente" estável, contrariando a tendência enunciativa pela escrita, que deve ocorrer

[...] em função de um sistema genérico preexistente, com o qual o escrevente já teve contato nas suas experiências de leitura. Esse conhecimento prévio faz com que o locutor tome o gênero (semi) conhecido como referência para a estruturação, organização e composição do seu próprio texto tanto para o respeitar, seguir como modelo, quanto para o transgredir. No trabalho da escrita, o escrevente vive de forma crucial [...] a tensão entre um estilo genérico, dado pelo paradigma e um estilo individual, singular, diferenciado, variado. (BRANDÃO, 2017, p. 158-159).

Recorrentemente, os gêneros são levados aos alunos com formas típicas padronizadas que servem de base para a produção de novas réplicas, ignorando-se as possibilidades de transgressão (como criação, espaço de intervenção) do escrevente no acontecimento discursivo, a partir de aspectos enunciativos sedimentados. O que, muitas vezes, o professor avalia como inadequado poderia ser um 
ponto de subjetivação pelo qual a voz do escrevente, sujeito sócio-histórico, emerge, de modo singular. Suscitar observações e discussões sobre esses pontos pode ser produtivo para a própria formação do sujeito ativo, autônomo, que realiza suas réplicas em função das respostas que deseja elaborar e não em função de respostas que sejam já previstas. Nesse sentido, o texto analisado anteriormente escapa dos diálogos previstos pela instituição, tanto no que diz respeito à forma, como ao conteúdo e ao estilo de linguagem. Isso não é necessariamente um problema. É uma outra maneira de abordagem da produção escrita.

Concluímos, pois, que os critérios de avaliação de uma produção escrita são limitados e podem ser questionados. Eles atuam no estabelecimento de uma expectativa docente que nem sempre se concretiza. Para além disso, quando tomados de maneira rígida e fechada, podem levar o corretor a ignorar o modo dialógico constitutivo do enunciado que avalia; modo este que poderia revelar como a leitura foi realizada pelo escrevente, qual a história de leitura desse escrevente e como ele articula sua constituição sócio-histórica ao acontecimento discursivo de sua réplica. Em outros termos, o modo dialógico constitutivo do texto pode revelar o próprio sujeito em processo ativo de diálogo com as vozes sociais que estão em interação. Onde a avaliação classificou "erro do aluno" pode haver uma marca de movimento dialógico que ele estabeleceu. A ideia de "erro" é, portanto, indicativa de falta de aprendizagem, segundo dada perspectiva escolar, e é indício de necessidade de reflexão pedagógica. O professor, ao detectar o que comumente chamaria de erro, pode refletir sobre as fragilidades de seu próprio fazer pedagógico, bem como pode tentar observar o modo como o aluno replicou, para auxiliá-lo a encontrar outros recursos linguístico-enunciativos com os quais venha a construir mais adequadamente suas réplicas, em função das esferas sociais, dos interlocutores, dos propósitos comunicativos etc.

Em convergência com o que elucidamos, referimo-nos a Daunay (2014), pesquisador francês no âmbito da didática da língua francesa, que defende uma concepção em estudos didáticos fundada na figura do imbecil, como sendo, de certa forma, uma perspectiva de investigação do lado do aluno. Para o autor (2014, p. 176): “À mes yeux, l'un des rôles importants que peut avoir la théorie en didactique est de penser les difficultés des élèves par la connaissance des limites du savoir — ce qui, en retour, permet de mieux penser le savoir." "Nesse sentido, o imbecil seria compreendido por uma perspectiva diferente daquela popularmente conhecida; a figura do imbecil teria função imprescindível no avanço da própria teoria didática, uma vez que: "l'imbécile est celui qui, d'un point de vue didactique, peut permettre d'interroger les objets d'enseignement, quand il aide à mettre le doigt sur les difficultés théoriques à cerner ces derniers."5 (DAUNAY, 2014, p. 176).

O interesse do autor não é especificamente detectar o erro, mas, sim, interrogar o status do erro. Essa interrogação se conjuga a uma atitude mais positiva e inclusiva perante as produções dos alunos, em uma concepção de educação como a de Paulo Freire (2005), segundo a qual o professor não é detentor do saber que depositaria conhecimento na cabeça dos alunos, considerados vazios, papel em branco a ser preenchido. Ao contrário disso, o professor seria um mediador importante, também ele em posição de aprendizagem.

Na proposta de análise de texto por seu viés dialógico, que se afasta da concepção de avaliação textual, as observações recairiam sobre aspectos inevitavelmente presentes nas réplicas escritas, tendo em vista o dialogismo inerente. O mais relevante, ao menos nessa etapa de abordagem de um texto, seriam os modos de diálogo, os pontos de emergência do sujeito, apesar de sua submissão aos aspectos estruturais do gênero, da linguagem e do discurso. O foco de observação seria o sujeito revelado em sua singularidade, embora constituído do outro — do sentido que não é inédito, mas,

4 A meu ver, um dos papéis importantes que a teoria didática pode ter é refletir sobre as dificuldades dos alunos pelo conhecimento dos limites do saber - o que permite melhor pensar sobre o próprio saber. (Tradução nossa).

$5 \mathrm{O}$ imbecil é aquele que, de um ponto de vista didático, pode permitir questionar os objetivos do ensino, quando ele ajuda a colocar o dedo sobre as dificuldades teóricas que cercam esses mesmos objetivos. (Tradução nossa). 
sim, resgatado pela memória discursiva, chegando-nos como sedimentado, naturalizado, já dado (PÊCHEUX, 2014). A ideia do "erro", nessa perspectiva, pode consistir em uma possibilidade de formação para os alunos e para os professores, tendo em vista que ambos buscariam entender por que um recurso ou modo de escrita seriam considerados como "erro", quais outras formas discursivas poderiam ser empregadas e quais efeitos de sentido cada uma delas produziria.

\section{Conclusão}

Como conclusão, salientamos a necessidade de práticas escolares que visem à formação de escreventes, professores e alunos. É preciso, nessa direção, investigar o porquê da classificação de uma produção textual como inapropriada ou incorreta. Muitas vezes, pelos aspectos de monofonia em que se apresenta, um texto é considerado insuficiente, o que nem sempre traduz os processos dialógicos explícita ou implicitamente materializados na escrita.

As produções escritas na escola, para ultrapassar uma concepção de "redação", meramente considerando a estrutura estabilizada do gênero, articulada a um trabalho singular do escrevente o aluno como produtor de textos — , poderiam ser abordadas pelo professor a partir do que lhes é intrínseco, o dialogismo. Avaliar pelo processo dialógico - o que culmina na própria necessidade de mudança do termo "avaliar" para, talvez, "analisar" - poderia contribuir para desarraigar o olhar normativo que constitui muitas práticas avaliativas em sala de aula, principalmente em relação aos textos dos alunos. Observar as produções discentes pelo que apresentam de constitutivo é uma atitude positivamente educativa; os desvios de norma poderiam ser tratados não apenas pela perspectiva do erro ou da falta, mas também das marcas dialógicas em que o sujeito emerge e que podem levá-lo a buscar outras formas de concretizar seu diálogo. Essas práticas só podem ocorrer em um contexto democrático, no qual a formação esteja em função do aluno e, sobretudo, do professor, em exercício reflexivo constante sobre sua prática e sua própria escrita.

A longo prazo, esse modo de abordar a escrita, como objeto de reflexão da prática docente e discente, passaria, a nosso ver, a outras atividades em sala de aula, em direção a uma relação professoraluno que leve em consideração a mediação docente, no sentido vygotskyano (VYGOTSKY, 2004), e o formar-se mutuamente, no sentido freiriano.

\section{Referências}

BAKHTIN, M. Estética da criação verbal. Tradução de Paulo Bezerra. 4. ed. São Paulo: Martins Fontes, 2003.

BAKHTIN, M. Marxismo e filosofia da linguagem. Tradução de Michel Lahud e Yara F. Vieira. 12. ed. São Paulo: HUCITEC, 2006.

BARROS, D. L. P. Dialogismo, polifonia e enunciação. In: BARROS, D. L. P.; FIORIN, J. L. Dialogismo, polifonia, intertextualidade: em torno de Bakhtin. 2. ed. São Paulo: Editora da Universidade de São Paulo, 2011. p. 1-10.

BRANDÃO, H. N. Atividade enunciativa na produção de linguagem: estereotipia e acontecimento discursivo. In: FANTI, M. da G.; BRANDÃO, H. N. (org.). Discurso: tessituras de linguagem e trabalho. São Paulo: Cortez, 2017.

DAUNAY, B. De l'imbécile en didactique du français: le point de vue de l'élève dans l'activité de recherche. In: DAUNAY, B.; DUFAYS, J. -L. dir.. Didactique du français: du côté des élèves. Comprendre les discours et les pratiques des apprenants. Louvain-la-Neuve: De Boeck, 2014. p. 175185. Disponível em: <https://hal.archives-ouvertes.fr/hal-01354230>. Acesso em: $1^{\mathrm{o}}$ nov. 2018. 
FRANCHI, C. Criatividade e gramática. In: FRANCHI, C. Mas o que é mesmo "gramática"?. São Paulo: Parábola Editorial, 2006.

FREIRE, P. Pedagogia do oprimido. 45. ed. São Paulo: Paz e Terra, 2005.

GERALDI, J. W. Portos de passagem. São Paulo: Martins Fontes, 1991.

GERALDI, J. W. Prática da leitura na escola. In: GERALDI, J. W. (org.). O texto na sala de aula. 4. ed. São Paulo: Ática, 2006. p. 57-79.

KOCH, I. As tramas do texto. 2. ed. São Paulo: Contexto, 2014.

PÊCHEUX, M. Discurso e ideologia(s). In: PÊCHEUX, M. Semântica e discurso: uma crítica à afirmação do óbvio. Tradução de Eni P. Orlandi et al. 5. ed. Campinas, SP: Ed. da Unicamp, 2014. p. 139-185.

PÊCHEUX, M. O discurso: estrutura ou acontecimento. Tradução Eni P. Orlandi. 7. ed. Campinas, SP: Pontes, 2015.

VYGOTSKY, L. S. Psicologia pedagógica. São Paulo: Martins Fontes, 2004. 
